\title{
Dynamic modelling of costs and health consequences of school closure during an influenza pandemic
}

Yiting Xue ${ }^{1,2^{*}}$, Ivar Sønbø Kristiansen ${ }^{3}$ and Birgitte Freiesleben de Blasio ${ }^{1,2}$

\begin{abstract}
Background: The purpose of this article is to evaluate the cost-effectiveness of school closure during a potential influenza pandemic and to examine the trade-off between costs and health benefits for school closure involving different target groups and different closure durations.
\end{abstract}

Methods: We developed two models: a dynamic disease model capturing the spread of influenza and an economic model capturing the costs and benefits of school closure. Decisions were based on quality-adjusted life years gained using incremental cost-effectiveness ratios. The disease model is an age-structured SEIR compartmental model based on the population of Oslo. We studied the costs and benefits of school closure by varying the age targets (kindergarten, primary school, secondary school) and closure durations (1-10 weeks), given pandemics with basic reproductive number of $1.5,2.0$ or 2.5 .

Results: The cost-effectiveness of school closure varies depending on the target group, duration and whether indirect costs are considered. Using a case fatality rate (CFR) of $0.1-0.2 \%$ and with current cost-effectiveness threshold for Norway, closing secondary school is the only cost-effective strategy, when indirect costs are included. The most cost-effective strategies would be closing secondary schools for 8 weeks if $R_{0}=1.5,6$ weeks if $R_{0}=2.0$, and 4 weeks if $R_{0}=2.5$. For severe pandemics with case fatality rates of $1-2 \%$, similar to the Spanish flu, or when indirect costs are disregarded, the optimal strategy is closing kindergarten, primary and secondary school for extended periods of time. For a pandemic with 2009 H1N1 characteristics (mild severity and low transmissibility), closing schools would not be cost-effective, regardless of the age target of school children.

Conclusions: School closure has moderate impact on the epidemic's scope, but the resulting disruption to society imposes a potentially great cost in terms of lost productivity from parents' work absenteeism.

Keywords: Influenza pandemic, School closure, Costs, Benefits, Simulation

\section{Background}

Influenza pandemics occur at irregular intervals and cause significant mortality and morbidity as well as substantial economic losses [1]. School closure is a possible strategy for mitigating transmission during the early phase of a pandemic when vaccine is not yet available. School closure has three main consequences: reducing the total disease burden, postponing the peak of

\footnotetext{
* Correspondence: yiting.xue@medisin.uio.no

'Department of Biostatistics, Institute of Basic Medical Sciences, University of Oslo, Oslo, Norway

${ }^{2}$ Department of Infectious Disease Epidemiology, Division of Infectious Disease Control, Norwegian Institute of Public Health, Oslo, Norway Full list of author information is available at the end of the article
}

infection and lowering the peak prevalence of the disease. Postponing the pandemic increases the time available for strain-specific vaccine production and distribution, and allows for more time to prepare for the peak workload in health care settings. Lowering the peak of the pandemic reduces the risk for overloading of health services and shortage of health care personnel due to influenza sickness.

Schools are thought to play a special role in transmission due to high contact rates among school children combined with higher susceptibility among children compared with adults. During the $\mathrm{A}(\mathrm{H} 1 \mathrm{~N} 1)$ pandemic in 2009, the estimated infection rate among school children

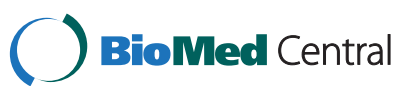


was significantly higher than that of the general population [2]. However, extended school closure is costly and may cause significant disruption to local communities by keeping working parents away from work and reducing school children's learning time. Quantifying the costs and benefits of school closure might help inform pandemic policy making.

There is currently no consensus about the expected health benefits of school closure [3]. Previous studies have investigated the impact of school closure either by analysing data from previous pandemics and epidemics or by computer simulation. The historical data approach includes studies of the 1918 influenza pandemic and suggests that school closure, combined with other interventions, lowered the disease burden and that the timing and duration of such interventions mattered $[4,5]$. A 2009 study of eight European countries indicated that during holidays and weekends the social contact patterns of children and the basic reproductive number were reduced by almost a quarter [6]. However, little effect on transmission was observed during a two-week kindergarten and primary school closure in Hong Kong in 2008 [7]. The estimated impact of school closure from computer simulations varies widely depending on model assumptions about how children contribute to influenza transmission, virus transmissibility and illness threshold when school closure is triggered [8-12]. Only a limited number of studies have explored the cost of school closure. Two studies focused on productivity loss of caretaking parents suggest that school closure for 12 weeks may cost $0.2-1 \%$ of GDP in the UK [13], and 4 weeks closure $0.1-0.3 \%$ of GDP in the US [14]. To reduce the economic loss from working parents, reactive short-term (1-4 weeks) school closure has been studied, where schools are shut when ICU units reach peak demand [15], but the optimal timing of such interventions may be difficult. Some studies have combined cost estimates with micro-simulation models [16-19] or dynamic compartmental models [20]. While the assumptions used in the studies differ, the general picture in the costeffectiveness is that school closure may be effective under high transmissibility, and/or high severity. Some of the studies were based on the characteristics of the 2009 H1N1 pandemic. Halder and co-workers [16] found that productivity losses due to sick leave and taking care of children when schools are closed were the dominating part of cost. A similar result was obtained in a study by Brown and co-workers [17] suggesting that the cost of school closure may far outweigh the cost saved from reducing the disease burden when the severity is low, regardless of the transmissibility.

In this study, we estimated potential costs and health benefits of school closure when implemented before substantial transmission of influenza among children has occurred (proactive school closure). We combined the cost estimates with a dynamic epidemiological transmission model, and determined the optimal closure strategy based on incremental cost-effectiveness ratios. Our study complements previous work on school closure by focusing on the age of the target school children, covering several scenarios for transmissibility, closure duration and severity. The study may be useful for public health authorities and may inform preparedness planning for future influenza pandemics.

\section{Methods}

\section{Background}

We modelled the impact of school closure in the context of a local community, using the capital city of Norway, Oslo, as the study setting. The city has a population size of 587000 , covering $12 \%$ of the Norwegian population. The unemployment rate is low (3.4\%) and women's participation in the labour force is high $(70 \%$ of women aged 15-74 are employed) [21]. The education system is composed of primary school for children aged 6 to 12 years and secondary school for children aged 13 to 18 years. The attendance rate in kindergarten is approximately $90 \%$ for children aged 1 to 5 [21].

\section{The disease model}

We considered a closed population of size $N=587000$, ignoring demography (births, deaths and immigration) since influenza epidemics are of very short duration. We divided the population into six age groups $(i=1-6)$ : $1-5$ years (6.7\%), 6-12 years (7.2\%), 13-18 years (6.9\%), $19-39$ years $(36.6 \%), 40-64$ years $(30.5 \%)$ and $65+$ years (12.2\%). We modelled a pandemic influenza using a deterministic dynamic SEIR (Susceptible-Exposed-InfectedRecovered) model [22]. People in each age group are divided into four mutually exclusive compartments: susceptible, infected symptomatically, infected asymptomatically, and recovered with immunity/dead from influenza (Figure 1). People progress from one compartment to another at the rates determined by the contact pattern and characteristics of the virus.

A susceptible individual $\left(S_{i}\right)$ becomes infected according to the age-specific force of infection $\lambda_{i}$. Newly infected individuals first enter the exposed state $\left(E_{i}\right)$ where they are infected, but not yet contagious, before developing either symptomatic infection $\left(I S_{i}\right)$ or asymptomatic infection $\left(I A_{i}\right)$. To obtain more realistic distributions of the exposed and infectious periods, we divided these periods into $n_{i}$ stages, where the progression from each stage occurs at a rate $r_{i}=n_{i} / D_{i}$, where $D_{i}$ is the mean duration of period $i=E, I S, I A$. This gives gamma distributed waiting times with shape parameters $k=n_{i}$ and scale parameters $\theta=D_{i} / n_{i}$. The mean duration of the exposed period was set to $1 / \sigma=1.9$ days $(17 ; 18)$ and 


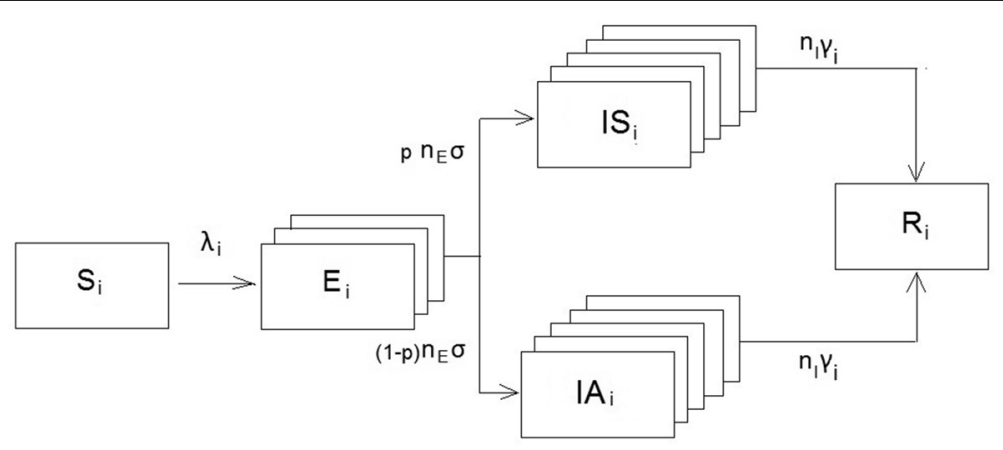

Figure 1 The dynamic influenza transmission model.

modelled in $n_{E}=3$ stages. Individuals in the last exposed stage were assumed to be infectious with infectivity $50 \%$ compared to the infectivity of symptomatic infection, as viral shedding increases after one day following transmission [23]. We assumed that a proportion $p=0.67$ will become symptomatically infected while a proportion $(1-p)=0.33$ develop asymptomatic infection $[24,25]$. The average duration of the symptomatic infectious period was set to $1 / \gamma_{c}=7$ days for children $(i=1,2)$ and $1 / \gamma_{a}=$ 5 days for adolescents/adults $(i=3-6) \quad[23,24,26]$ and modelled in $n_{I}=5$ stages. Infectivity during the stages was set at $100 \%, 100 \%, 50 \%, 30 \%$ and $15 \%$ in accordance with data showing that viral transmission peaks during the early period after symptoms develop [23,27]. We assumed that asymptomatic infections are $50 \%$ as infectious per contact as symptomatic infections [23], but with similar duration and infectivity profile as symptomatic infections. However, other studies have found that asymptomatically infected individuals might be less important for transmission [28]. At the end of the infectious stage, people either recover or are removed from the system due to death. Individuals who have recovered from infection $\left(R_{i}\right)$ are assumed be protected from reinfection during the course of the simulation. The system can be described by a set of differential equations for each age group $i=1-6$ :

$$
\begin{aligned}
& \frac{d S_{i}}{d t}=-S_{i} \lambda_{i} \\
& \frac{d E_{1 i}}{d t}=S_{i} \lambda_{i}-n_{E} \sigma E_{1 i} \\
& \frac{d E_{l i}}{d t}=n_{E} \sigma E_{(l-1) i}-n_{E} \sigma E_{l i} \quad \forall l=2,3 \\
& \frac{d I A_{1 i}}{d t}=(1-p) n_{E} \sigma E_{3 i}-n_{I} \gamma_{i} I A_{1 i} \\
& \frac{d I A_{m i}}{d t}=n_{I} \gamma_{i} I A_{(m-1) i}-n_{I} \gamma_{i} I A_{m i} \quad \forall m=2 \ldots 5 \\
& \frac{d I S_{1 i}}{d t}=p n_{E} \sigma E_{3 i}-n_{I} \gamma_{i} I S_{1 i} \\
& \frac{d I S_{n i}}{d t}=n_{I} \gamma_{i} I S_{(n-1) i}-n_{I} \gamma_{i} I S_{n i} \quad \forall n=2 \ldots 5
\end{aligned}
$$

$$
\begin{aligned}
\frac{d R_{i}}{d t} & =n_{I} \gamma_{i}\left(I A_{5 i}+I S_{5 i}\right) \\
\lambda_{i} & =\sum_{j=1}^{6} \beta_{i j}\left(\alpha_{E} E_{j}+\sum_{k=1}^{5}\left(\alpha_{I A}(k) I A_{k j}+\alpha_{I S}(k) I S_{k j}\right)\right)
\end{aligned}
$$

Where $\lambda_{i}$ is the per capita force of infection for a susceptible individual in age group $i$ to become infected and $\beta_{i j}$ is the transmission rate from age group $j$ to age group $i$ The age-specific force of infection $\lambda_{i}$ is a product of age-specific contact rates, the prevalence of the infectious people $\left(I_{i}\right)$ and the probability of transmission given contact $(q)$. We obtained the contact rates based on conversational data from a study in the Netherlands [29]. We employed a WAIFW matrix ("Who-acquiresinfection-from-whom" matrix) based on the contact rates between age groups. The basic reproductive number $\left(R_{0}\right)$ was calculated as the largest eigenvalue in the next generation matrix (23). The basic reproductive number is "the average number of secondary cases arising from an average primary case in an entire susceptible population" [22]. Through varying the value of $q$, we can produce the desired $R_{0}$.

The differential equations were solved numerically using a fourth-order Runge-Kutta method with adaptable step size in Matlab 2009. It is unclear whether cross-immunity from past exposure to influenza will provide protection against a future pandemic strain. We assumed that the population was fully susceptible to the novel pandemic strain at the beginning of the simulation. Transmission was initiated at day $t_{i}=1$ by moving a proportion of $10^{-6}$ of susceptible in each age class into the exposed class. The simulation was run for a period of $t=250$ days.

The transmissibility of a future pandemic strain is a major source of uncertainty. For this reason, we tested the model with three different basic reproductive numbers $R_{0}=1.5,2.0$ and 2.5. The school closure intervention was initiated when the prevalence of symptomatic infections had reached $1 \%$ of the population and was 
assumed to have full impact from this point in time. In the baseline scenario (scenario A), we assumed a 90\% reduction in contacts among isolated children/adolescents with individuals in their own age group and a $25 \%$ decrease in contacts with other age groups. We did not consider changes in the contact patterns of affected parents taking care of children at home in this baseline scenario.

\section{One-way sensitivity analysis}

To account for some of the uncertainty in the model, we performed additional simulations varying assumptions about: the behaviours of care-taking parents, the behaviours of dismissed student during school closure and the case fatality rate (CFR).

In Scenario B, we introduced a $50 \%$ reduction in same age contacts among care-taking parents absent from work; in Scenario $\mathrm{C}$ we reduced the same age contact of dismissed children by $50 \%$ instead of $90 \%$ in the base case, and by $10 \%$ with other age groups instead of $25 \%$ to simulate low compliance among affected children; in Scenario $\mathrm{D}$ we increased the case fatality rate (CFR) by a factor of 10 compared to the baseline scenarios, using CFR of 1-2\% in children and adults below 65 years similar to the level observed during the Spanish flu [30]; in Scenario E we reduced the CFR by a factor of 10 relative to the baseline scenarios, using CFR of $0.01-0.02 \%$ to simulate a mild pandemic. Finally, in Scenario $F$ we modelled a pandemic with similar characteristics as the $2009 \mathrm{H} 1 \mathrm{~N} 1$ pandemic. In these simulations, we assumed an $R_{O}$ of $1.3 .60 \%$ of the populations in the $65+$ year old age group and $10 \%$ of the $40-64$ year old age group were assumed to have prior immunity. We also reduced the case fatality rate in accordance with Norwegian data showing that approximately 30 people died from H1N1 influenza (http://www.fhi.no/dokumenter/6cbae0eece.pdf).

\section{The economic model}

The costs of school closure comprised parents' productivity losses and students' loss of learning. Avoided costs resulted from less use of health care resources, less loss of productivity and less use of energy in school buildings. Health benefits were expressed as gained qualityadjusted life-years (QALYs). Productivity loss due to illness and health benefits were included for cases of mortality and cases of morbidity. We used 2008 data (US\$1.00=NOK7.00 [21]) for all economic calculations. All future costs and health outcomes were discounted by $4 \%$ as recommended by the Ministry of Health.

\section{Costs of school closure}

Absence from school means lost learning hours and potentially permanent loss of learning and income [31,32]. We searched the literature and databases, and contacted experts in education and educational economics. We were unable to identify any studies that directly address the issue of learning consequences of school closure. We assumed that this was the case only for students in upper secondary schools while children in kindergarten, primary and lower secondary school have no loss of learning from some weeks' school closure. Most schools in Norway are public and free of charge, but some private schools offer upper secondary school education. Here, the tuition fee for one school year comprising 40 weeks was $\$ 8143$, which is equivalent to $\$ 203$ per week. We used this amount as an estimate of the value of lost learning.

School closure will keep working parents at home to care for children who are affected by the intervention. We assumed that students over 12 years do not need parental care during school closures. Similar to Sadique's study [13], we assumed that only one parent is needed to care for children in a single household during school closure. Consequently, we distinguished between children living together with a single parent and with two parents. The percentages of both parents working were $66 \%$ among married couples with children and 78\% among co-habitant couples with children (personal communication with Statistics Norway, 12 March, 2010). The percentage of working single parents was assumed to be the same as the percentage of working people in the same gender group $(90 \%$ for men and $85 \%$ for women) [21]. We multiplied these percentages by the number of married couples, co-habitant couples and single parents, respectively. The sum of the products was taken as the number of individuals who would be absent from work during school closure.

We estimated the productivity losses from parents' work absenteeism by multiplying the number of individuals that would need to be away from work during school closure with the number of days when schools are closed under different scenarios. The value of one day's work was set equal to the national average wage rate (US\$290 per day) plus $40 \%$, which accounts for the value of productivity that is not returned to the worker as wages, including employer tax, payment for holiday and pension contributions.

\section{Reduction of total cost due to school closure}

The model outcome for symptomatically infected was divided into four types: mild cases who receive no medical care, moderate cases who receive outpatient service, severe cases who are hospitalized and fatal cases. Since the severity of a future pandemic is unknown, we used estimates of case fatality rates and health outcomes based on data from previous pandemics [33] (Table 1). We assumed that people with asymptomatic infection incur no economic costs, and therefore they were ignored in the economic analyses. The medical costs were estimated as the sum of mild, moderate and severe 
Table 1 Model parameters

\begin{tabular}{|c|c|c|c|}
\hline & Mean & Distribution & Referen \\
\hline \multicolumn{4}{|l|}{ Demographic data } \\
\hline Population by age & & & 15 \\
\hline $1-5$ years old & $6.63 \%$ & & \\
\hline 6 -12 years old & $7.17 \%$ & & \\
\hline 13-19 years old & $6.86 \%$ & & \\
\hline $20-39$ years old & $36.65 \%$ & & \\
\hline 40-64 years old & $30.46 \%$ & & \\
\hline $65+$ years old & $12.24 \%$ & & \\
\hline $\begin{array}{l}\text { Percentage of adult population affected by } \\
\text { school closure: }\end{array}$ & & & 15 \\
\hline kindergarten ( $1-5$ years old $)$ & $4.54 \%$ & & \\
\hline kindergarten/primary school (1-11 years old) & $10 \%$ & & \\
\hline \multicolumn{4}{|l|}{ Disease parameters } \\
\hline Basic reproductive number $\left(R_{0}\right)$ & $1.5,2.0,2.5$ & & $31 ; 32 ; 8$ \\
\hline Mean duration of exposed period & 1.9 days & & $17 ; 18$ \\
\hline Mean duration of infectious period & $\begin{array}{l}7 \text { days }(<12 \text { years }) \\
5 \text { days ( } 12+\text { years })\end{array}$ & & $17 ; 18 ;$ \\
\hline Proportion asymptomatic ( $p)$ & $33 \%$ & & \\
\hline Infectivity (last exposed stage) & $50 \%$ & & 19 \\
\hline Infectivity (in the five infectious stages) & $100 \%, 100 \%, 50 \%, 30 \%, 15 \%$ & & $19 ; 20$ \\
\hline
\end{tabular}

\section{Mixing assumptions}

\section{Scenario A (baseline)}

Reduction in contact rate between dismissed children of same/other age groups

Reduction in contact rate among care-taking parents and same age group

\section{Scenario B}

Reduction in contact rate between dismissed children of same/other age groups

Reduction in contact rate among care-taking parents and same age group

\section{Scenario C}

Reduction in contact rate between dismissed children of same/other age groups

Reduction in contact rate among care-taking parents and same age group

\section{Disease outcomes}

Outcomes per 1000 cases by age groups ${ }^{a}$

Outpatient

Inpatient

Death

\section{Economic parameters}

Cost of energy saving (1000 US\$)

Cost of lost learning (1000 US\$)

Proportion of productivity loss catching up Average cost per self-care person (US\$)
$90 \% / 25 \%$

$0 \%$

$90 \% / 25 \%$

$50 \%$

$50 \% / 10 \%$

$0 \%$

Uniform ((494-574), (369-410), $(487-506))$

((1-8), (2-13), (21-37))

$((0-2),(0-4),(11-15))$

1439

25797

$15 \%$

43

$\begin{array}{ll}\text { Gamma }^{b} & a=16 ; \beta=90 \\ \text { Gamma } & a=16 ; \beta=1612 \\ \text { Uniform } & \text { range [0: 30\%] } \\ \text { Normal } & \sigma=3.57\end{array}$

Oslo Municipality Bjørknes private school 
Table 1 Model parameters (Continued)

\begin{tabular}{lllll}
\hline Average cost per out-patient (US\$) & 59 & Normal & $\sigma=4.92$ & Den norske legeforening \\
Average cost per in-patient (US\$) & 5211 & Normal & $\sigma=434$ & 26 \\
Average wage per day (US\$) & 290 & Normal & $\sigma=24$ & 15 \\
\hline
\end{tabular}

${ }^{a}$ Age groups were grouped by $1-18$ years old, $19-64$ years old and $65+$ years old.

${ }^{\mathrm{b}} f(x ; k, \theta)=x^{k-1} \frac{e^{-x / \theta}}{\theta^{k} \Gamma(k)}$ where $\Gamma$ is the Gamma function.

cases, multiplied by their respective unit costs. The unit costs were taken from a recent study of influenza costs in Norway [34].

Loss of productivity associated with influenza has two components: the loss of working hours for the symptomatically infected and the loss of potential productivity for the fatal cases. Productivity losses due to morbidity were valued in the same way as parents' work absenteeism. Productivity losses due to mortality were valued according to the remaining life expectancy at the relevant ages, discounted by $4 \%$ and with the assumption that people participate in the work force until age 65 .

The avoided school heating cost was estimated using data from the Educational Buildings and Property Department in Oslo municipality.

\section{Health benefits}

Assuming that school closure will reduce the number of symptomatic and fatal influenza cases, we expressed the health benefits from school closure in terms of qualityadjusted life years (QALYs). For those who are symptomatically infected, we used utility scores from a Canadian study [35]. These utility scores represent the utility people have on each of the seven days since the onset ( 0 for worst possible health and 1 for normal health). The utilities are $0.41,0.47,0.58,0.67,0.73,0.78$ and 0.81 for day 1 to day 7 , respectively. For those who died due to the illness, the QALY loss was calculated from the remaining life expectancy at the age of death predicted by the disease model and the discount factor.

\section{Intervention strategy scenarios}

We explored the costs and benefits of intervention policies with different durations (from 1 to 10 weeks) and for different target groups (closing kindergarten alone, primary school alone, secondary school alone, kindergarten and primary school or all three).

\section{Uncertainty in cost-effectiveness estimates}

To quantify the uncertainty in the cost-effectiveness ratios, we performed a probabilistic sensitivity analysis (number of simulations $=1000$ ) on the selected strategy for $R_{O}=1.5,2.0$ and 2.5, incorporating the uncertainty in the demographic parameters, disease parameters, disease outcomes and economic parameters (Table 1). In addition, we reduced the work loss of care-taking parents by $0-30 \%$ (uniform distribution) assuming that some children were cared for by relatives or other persons, or that part of their work loss could be carried out through work from home or through work at a later time. The results were presented graphically by means of cost-effectiveness acceptability curves (Additional file 1: e-Figure 1).

\section{Results}

Epidemiological impact of school closure

Figures 2, 3 show the epidemiological results of school closure. In the absence of intervention, our baseline model predicts 216000,300000 and 340000 symptomatic infections in the Oslo population for $R_{O}=1.5,2.0$ and 2.5 pandemics, corresponding to clinical attack rates (AR) of $37 \%, 51 \%$ or $58 \%$, respectively (Table 2 ). The relative effectiveness of the interventions increased with lower $R_{O}$ values but required longer closure time to achieve the health benefits (Figure 3). School closure lowers the attack rate with up to $7-22 \%, 4-13 \%$ and $2-9 \%$ with $R_{0}=1.5,2.0$ or 2.5 ; these reductions are achieved after approximately 10,8 and 7 weeks of closure (Figure 3 ). The peak prevalence of symptomatic infections was reduced correspondingly with up to $7-36 \%$, $6-26 \%$ and $5-20 \%$. To reach maximum reduction, school closure must be maintained for some weeks and beyond the point in time when the mitigated pandemic passes through its natural peak (Additional file 1: e-Figure 2). If schools are re-opened earlier, the pandemic will rebound. This will also happen if the intervention stops in the wake of the pandemic, provided the effective reproductive number of the un-mitigated pandemic is still above 1. Consequently, the maximum delay of the peak occurred for intermediate closure durations. The peak was delayed by up to $8-10$ days $\left(R_{O}=1.5\right)$, and to 4-5 days for $R_{O}=2.0,2.5$. To avoid restarting the epidemic, we found that closure must be effective for at least 3-4 week for $R_{O}=1.5$, and 2-3 weeks when the transmissibility is higher.

The baseline scenarios gave an estimated 93 000147000 outpatient visits, $1900-3100$ hospitalizations and 590-990 deaths (Table 2). The simulation runs showed that a 12-week school closure would reduce the attack rate by up to $22 \%, 14 \%$ and $7 \%$ for $R_{O}=1.5,2.0$ and 2.5 pandemics. The reductions in disease outcomes 


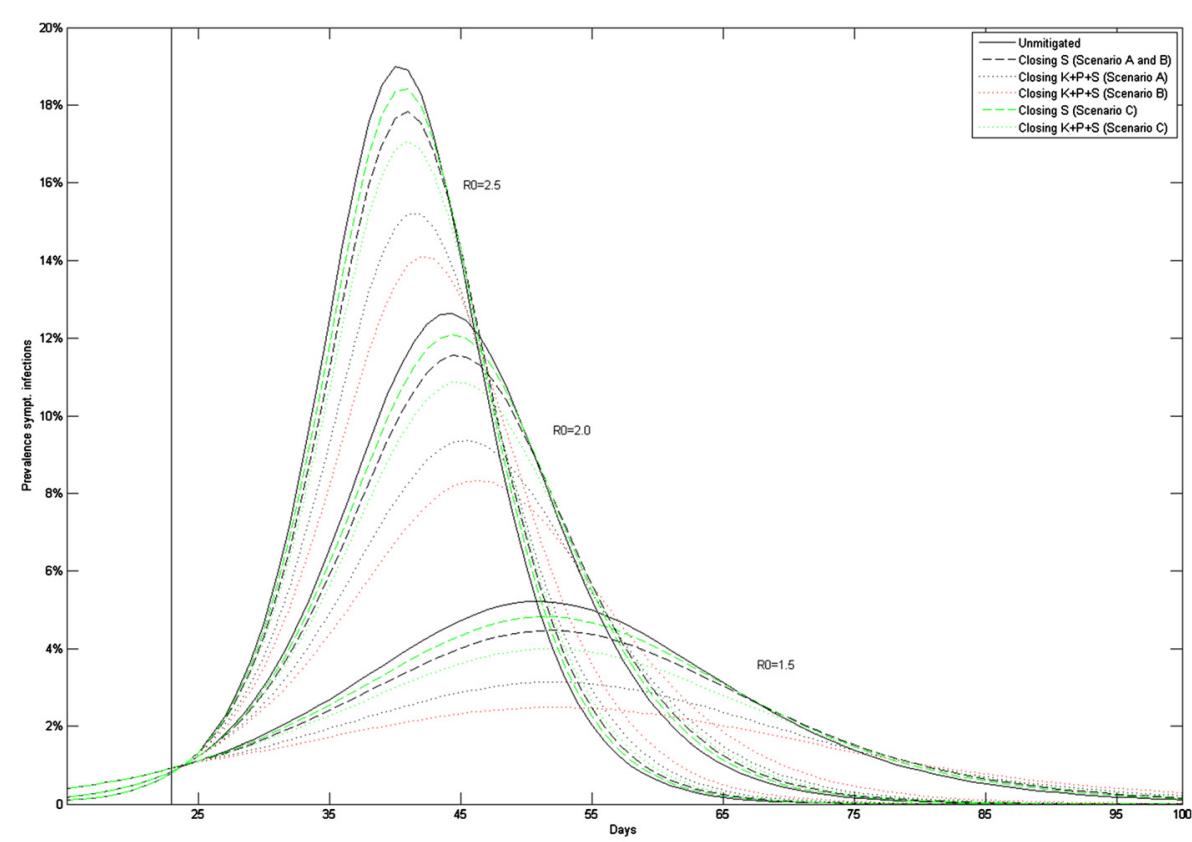

Figure 2 Epidemic curves showing the prevalence of symptomatic infections for unmitigated pandemic versus implementing a 12-week school closure with $R_{0}=1.5,2.0$ and 2.5.

followed the reductions in attack rate, with slightly higher reductions in outpatients $(6 \%-25 \%)$ and slightly lower reductions in inpatients and deaths $(4 \%-20 \%)$ for a 12-week closure with $R_{0}=1.5,2.0$ or 2.5 in the base case.

\section{Economic impact}

Without school closure, the total health care costs would be $\$ 21$ million, \$29 million and \$33 million, productivity losses due to mortality would be $\$ 313$ million, $\$ 428$ million and $\$ 480$ million and productivity losses due to morbidity $\$ 102$ million, $\$ 139$ million and $\$ 155$ million, for basic reproductive numbers of 1.5, 2.0 and 2.5 (Tables 3, 4 and 5). Depending on the type and duration of school closure, the cost of lost learning would be $\$ 0-32$ million, while the cost of lost productivity were in the range of $\$ 0-630$ million, and reduction in school heating costs varied between $\$ 0.18$ and 5.4 million. The total influenza related costs would range from $\$ 435$ million to $\$ 1285$ million from the societal perspective (Tables 3, 4 and 5).

Health benefits from school closure would range from 15 QALYs to 2056 QALYs depending on $R_{0}$, the age target group and the duration of school closure (Tables 3, 4 and 5). Our results indicate that in the baseline scenario, closing secondary schools for 8,6 and 4 weeks, when $R_{0}$ is 1.5 , 2.0 and 2.5 respectively, is the most cost-effective strategy when indirect costs are accounted for. Closing secondary schools is cost-effective given a wide range of costeffective threshold ratios, as shown by cost-effectiveness acceptability curves (Additional file 1: e-Figure 1). The strategy of closing secondary was also cost-effective for varying closure durations (data not shown).

\section{Sensitivity analyses}

The sensitivity analyses confirm that closing secondary schools is the optimal strategy from a societal perspective, unless the case fatality rate (CFR) is very high.

Scenario B: Reduced (adult-adult) contact among care-taking parents. We found increased effect of school closure relative to the baseline scenarios. The estimated reduction in the attack rate compared to an unmitigated pandemic was $8-30 \%, 4-16 \%$, and $3-10 \%$, for $R_{0}=1.5$, 2.0 and 2.5 pandemics, respectively (Table 2 ). The corresponding optimal strategies were closing secondary schools with durations of 8 weeks, 6 weeks and 4 weeks, identical to the findings in the baseline scenario (Additional file 1: e-Table 1; I-III).

Scenario C: Reduced compliance of dismissed children/students to stay at home. The simulations showed an overall small effect of school closure. The estimated maximum reduction in the attack rate compared to an unmitigated pandemic ranged between $3-11 \%, 2-6 \%$ and $2-3 \%$ for $R_{0}=1.5,2.0$ and 2.5 , respectively (Table 2 ). The optimal strategies were closing secondary schools for 7 , 4, and 3 weeks (Additional file 1: e-Table 2; I-III), indicating a shorter optimal period of one week compared with the baseline model for $R_{0}=1.5$ and 2.5.

Scenario D: Increasing the case fatality rate by a factor of 10. This means increasing the severity of the pandemics to levels similar to those observed during the 


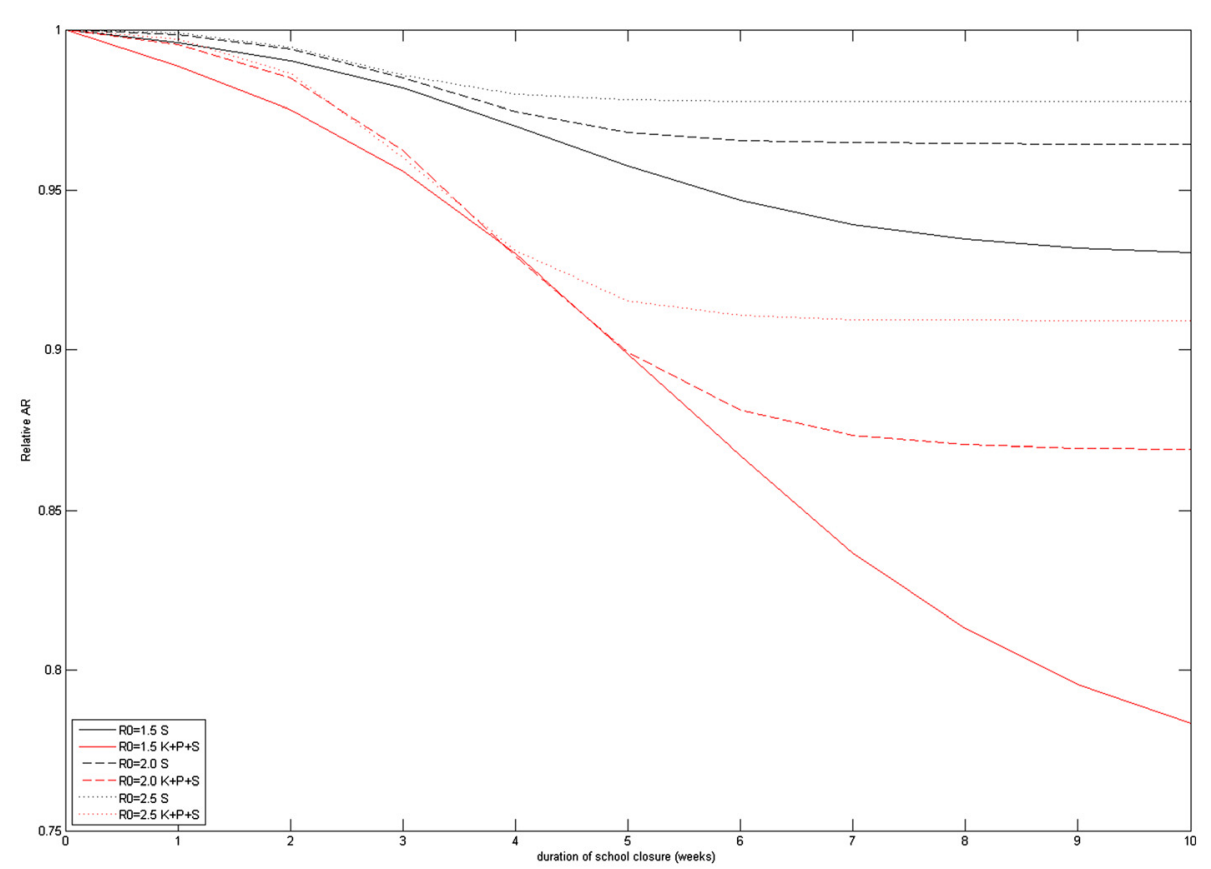

Figure 3 The relative attack rate compared to an unmitigated pandemic as function of school closure duration (number of closure weeks).

Spanish Flu [36]. In this case, the optimal strategies were closing kindergartens, primary and secondary schools for 9 weeks if $R_{0}=1.5$, 7 weeks if $R_{0}=2.0$, and 5 weeks if $R_{0}=2.5$ (Additional file 1: e-Table 3).

Scenario E: Decreasing the case fatality rate by a factor of 10. In this case, when $R_{0}=1.5$, closing secondary school for 6 weeks is most cost-effective. Otherwise, there is no cost-effective strategy among the strategies we examined (Additional file 1: e-Table 4).

Scenario F: Pandemic with 2009 H1N1 characteristics. The results show that the added cost of school closure was higher than not closing schools, regardless of the age target of school children. Consequently school closure would not have been cost-effective during the 2009 H1N1 pandemic (Additional file 1: e-Table 5).

\section{Discussion}

Our study shows that school closure during influenza pandemic has a moderate impact on the total disease burden. The cost-effectiveness of school closure varies considerably across different strategies with different target groups and durations. Generally we found that for $R_{0}=1.5,2.0$ and 2.5 pandemics with case fatality rates of $0.1-0.2 \%$, only those strategies involving closure of secondary schools were cost-effective from a societal point of view. The study shows that optimal school closure depends on the transmissibility and severity of the pandemic and may provide guidance to local policy planning. The optimal duration of closing secondary schools is shorter ( 4 weeks) with $R_{0}=2.5$ compared to 8 weeks with $R_{0}=1.5$. In contrast, school closure involving primary schools and kindergartens incur substantial economic costs due to lost productivity of care-taking parents. Consequently, most school closure strategies cannot be considered cost-effective (Tables 3, 4 and 5) at current values of quality adjusted life-years in Norway [37]. However, school closure involving children in need of parental care may be indicated when case fatality rates are high, for instance in the event of a future pandemic with an avian (H5N1) virus.

We also simulated a pandemic with characteristics of the $2009 \mathrm{H} 1 \mathrm{~N} 1$ pandemic. Our results suggest that school closure as a single intervention would not have been costeffective during the recent pandemic. This finding is in agreement with results by Brown and co-workers [17], who found that the net costs of school closure during the 2009 H1N1 pandemic would have been substantially higher than the cost savings from preventing influenza disease. However, other studies indicate that school closure might have been cost-effective, despite the low severity and low transmissibility of the 2009 H1N1 pandemic. Halder and co-workers [16] found that short-duration school closure of 2 to 4 weeks would be relatively costeffective while in general school closure intervention as a single strategy would be less efficient than strategies involving widespread use of antivirals, and Araz and coworkers found that a $0.5 \%$ prevalence closure trigger followed by a 12 week closure would be cost-effective [20]. 
Table 2 Disease outcomes given $R_{0}=1.5,2.0$ and 2.5

\begin{tabular}{|c|c|c|c|c|c|c|c|c|c|c|c|c|}
\hline \multirow[t]{2}{*}{ School closure of 12 weeks } & \multicolumn{4}{|c|}{$\mathrm{R} 0=1.5$} & \multicolumn{4}{|c|}{$\mathrm{R} 0=\mathbf{2 . 0}$} & \multicolumn{4}{|c|}{$\mathrm{RO}=2.5$} \\
\hline & outp. & inp. & deaths & $\mathrm{AR}(\%)$ & outp. & inp. & deaths & $\mathrm{AR}(\%)$ & outp. & inp. & deaths & $A R(\%)$ \\
\hline No intervention & 92779 & 1929 & 584 & 37 & 128932 & 2738 & 844 & 51 & 146088 & 3150 & 983 & 58 \\
\hline \multicolumn{13}{|l|}{ Scenario A (baseline) } \\
\hline K & 87388 & 1846 & 560 & 35 & 123904 & 2673 & 825 & 49 & 141642 & 3098 & 968 & 56 \\
\hline$P$ & 83081 & 1779 & 540 & 33 & 121245 & 2638 & 815 & 49 & 140075 & 3080 & 962 & 56 \\
\hline $\mathrm{S}$ & 85718 & 1813 & 550 & 34 & 123784 & 2665 & 822 & 49 & 142328 & 3101 & 968 & 57 \\
\hline$K+P$ & 77605 & 1692 & 514 & 31 & 115823 & 2566 & 793 & 47 & 135161 & 3022 & 945 & 54 \\
\hline \multirow[t]{4}{*}{$\mathrm{K}+\mathrm{P}+\mathrm{S}$} & 69989 & 1559 & 474 & 29 & 109800 & 2477 & 767 & 44 & 130661 & 2962 & 927 & 53 \\
\hline & \multicolumn{12}{|c|}{ SENSITIVITY ANALYSIS } \\
\hline & \multicolumn{4}{|c|}{$\mathrm{R} 0=1.5$} & \multicolumn{4}{|c|}{$\mathrm{R} 0=2.0$} & \multicolumn{4}{|c|}{$\mathrm{R} 0=2.5$} \\
\hline & outp. & inp. & deaths & $\mathrm{AR}(\%)$ & outp. & inp. & deaths & $\mathrm{AR}(\%)$ & outp. & inp. & deaths & $A R(\%)$ \\
\hline \multicolumn{13}{|l|}{ Scenario B } \\
\hline K & 85200 & 1798 & 546 & 34 & 122669 & 2645 & 817 & 49 & 140911 & 3082 & 963 & 56 \\
\hline$P$ & 79765 & 1707 & 519 & 32 & 119377 & 2597 & 803 & 48 & 138986 & 3056 & 955 & 55 \\
\hline $\mathrm{S}$ & 85718 & 1813 & 550 & 34 & 123784 & 2665 & 822 & 49 & 142328 & 3101 & 968 & 57 \\
\hline$K+P$ & 71608 & 1559 & 475 & 29 & 112224 & 2487 & 770 & 45 & 133028 & 2975 & 932 & 53 \\
\hline$K+P+S$ & 64030 & 1423 & 434 & 26 & 105671 & 2387 & 740 & 43 & 128221 & 2910 & 912 & 52 \\
\hline \multicolumn{13}{|l|}{ Scenario C } \\
\hline K & 89954 & 1885 & 572 & 36 & 126502 & 2707 & 835 & 50 & 144110 & 3127 & 976 & 57 \\
\hline$P$ & 87441 & 1847 & 560 & 35 & 125354 & 2691 & 830 & 50 & 143677 & 3121 & 974 & 57 \\
\hline S & 89346 & 1873 & 568 & 36 & 126696 & 2706 & 835 & 50 & 144607 & 3131 & 977 & 57 \\
\hline$K+P$ & 84498 & 1801 & 547 & 34 & 122774 & 2657 & 820 & 49 & 141574 & 3097 & 967 & 56 \\
\hline $\mathrm{K}+\mathrm{P}+\mathrm{S}$ & 80744 & 1738 & 528 & 33 & 120292 & 2621 & 810 & 48 & 139934 & 3075 & 961 & 56 \\
\hline
\end{tabular}

Outp= outpatient. Inp= inpatient. $A R=$ attack rate.

Scenario $A$ is the base case scenario; scenario $B$ included a $50 \%$ reduction in contacts among care-taking parents absent from work based on scenario $A$; scenario $C$ reduced the compliance to $50 \%$ from scenario $A$.

Our findings are similar to other computer simulation studies $[8-10,17,36]$ and a surveillance data study from Hong Kong [7], all of which indicate that the impact of school closure on the pandemic is modest. In general we found that school closure peak timing was delayed with only few days compared with that of an unmitigated pandemic. The delay increased with lower transmissibility. The maximum delay was observed for intermediate closure durations, when the epidemic re-started influenced by the higher transmissibility of the unmitigated pandemic $\left(R_{e f f}>1\right)$. A micro-simulation study by Lee and co-workers [9] also show that intermediate duration closure produces the longest delays. However, their observed delay for long closure duration was longer: 4-8 days for system wide school closure for $R_{0}=1.4-2.4$. One possible explanation for the shorter delay in our study is that we assume that the whole population is interacting, while we did not model the individual transmission processes. In addition, individuals in our model generally mix most with individuals in their own age group. Therefore, there is a tendency that the epidemic in school children develops "independently" of how the epidemic develops in the other age groups, and school closure has only small impact on the disease burden in the population that is not directly affected by the intervention. We have performed additional simulations using a lower closure trigger of $0.5 \%$ instead of the $1 \%$ assumed in the baseline scenario (results not shown). These simulations show that an earlier trigger increases the maximum delay by approximately one third, while the peak timing during long duration closure increased only little.

Our approach is analogous to a recent study by Araz and co-workers [20], using a dynamic compartmental model combined with calculations of incremental costeffectiveness ratios to select the preferred policy. They studied pandemics with transmissibility in the range $R_{0}=1.1-2.1$, using various closure triggers and fixed school closure durations of 1-24 weeks or prevalence-based reopening triggers. They found that in low transmissibility scenarios, early triggers combined with long closure duration of 12-24 weeks were preferred, regardless of severity; for high transmissibility scenarios, later triggers combined with 8-18 weeks closure were preferred. In 
Table 3 Cost and health outcome according to type and duration of school closure when $\boldsymbol{R}_{\boldsymbol{O}}=\mathbf{1 . 5}$

\begin{tabular}{|c|c|c|c|c|c|c|c|c|c|c|c|}
\hline $\begin{array}{l}\text { Target } \\
\text { school }\end{array}$ & $\begin{array}{l}\text { Duration } \\
\text { (weeks) }\end{array}$ & $\begin{array}{l}\text { Cost of } \\
\text { lost learning } \\
(\$ 1000)\end{array}$ & $\begin{array}{l}\text { Lost productivity } \\
\text { due to school } \\
\text { closure }(\$ 1000)\end{array}$ & $\begin{array}{l}\text { Energy } \\
\text { savings } \\
(\$ 1000)\end{array}$ & $\begin{array}{l}\text { Health } \\
\text { care costs } \\
(\$ 1000)\end{array}$ & $\begin{array}{l}\text { Lost productivity } \\
\text { due to fatal } \\
\text { cases }(\$ 1000)\end{array}$ & $\begin{array}{l}\text { Lost productivity } \\
\text { due to sickness } \\
(\$ 1000)\end{array}$ & $\begin{array}{l}\text { Total cost } \\
(\$ 1000)\end{array}$ & $\begin{array}{l}\text { QALY gains } \\
\text { (compared to } \\
\text { no intervention) }\end{array}$ & $\begin{array}{l}\text { Cost per QALY } \\
\text { (compared to } \\
\text { no intervention) }\end{array}$ & ICER \\
\hline 0 & 0 & 0 & 0 & 0 & 20591 & 312958 & 101576 & 435125 & 0 & & \\
\hline 3 & 6 & 19350 & 0 & 1080 & 19557 & 298239 & 97846 & 433912 & 507 & -2395 & \\
\hline 3 & 7 & 22575 & 0 & 1260 & 19410 & 296139 & 97312 & 434175 & 579 & -1641 & 3648 \\
\hline 3 & 5 & 16125 & 0 & 900 & 19766 & 301213 & 98600 & 434804 & 404 & -796 & Dominated \\
\hline 3 & 8 & 25800 & 0 & 1440 & 19318 & 294825 & 96978 & 435481 & 624 & 570 & 28929 \\
\hline 3 & 4 & 12900 & 0 & 720 & 20008 & 304661 & 99474 & 436323 & 286 & 4193 & Dominated \\
\hline 3 & 1 & 3225 & 0 & 180 & 20509 & 311792 & 101278 & 436625 & 40 & 37316 & Dominated \\
\hline 3 & 9 & 29025 & 0 & 1620 & 19264 & 294064 & 96784 & 437517 & 650 & 3679 & 77819 \\
\hline 3 & 3 & 9675 & 0 & 540 & 20235 & 307897 & 100293 & 437560 & 174 & 13962 & Dominated \\
\hline 3 & 2 & 6450 & 0 & 360 & 20403 & 310287 & 100897 & 437678 & 92 & 27727 & Dominated \\
\hline 3 & 10 & 32250 & 0 & 1800 & 19237 & 293672 & 96684 & 440043 & 664 & 7412 & 187991 \\
\hline 2 & 1 & 0 & 26795 & 188 & 20495 & 311614 & 101261 & 459977 & 47 & 531474 & \\
\hline 1 & 1 & 0 & 36194 & 174 & 20530 & 312120 & 101383 & 470054 & 29 & 1193056 & \\
\hline 2 & 2 & 0 & 53591 & 376 & 20385 & 310094 & 100909 & 484603 & 100 & 496745 & \\
\hline 4 & 1 & 0 & 62989 & 362 & 20440 & 310857 & 101085 & 495009 & 73 & 817647 & \\
\hline 5 & 1 & 3225 & 62989 & 542 & 20367 & 309817 & 100816 & 496672 & 109 & 564499 & \\
\hline 1 & 2 & 0 & 72388 & 348 & 20453 & 311044 & 101138 & 504674 & 67 & 1039847 & \\
\hline 2 & 3 & 0 & 80386 & 564 & 20210 & 307651 & 100342 & 508024 & 185 & 395026 & \\
\hline 2 & 4 & 0 & 107181 & 752 & 19950 & 304039 & 99504 & 529922 & 310 & 305814 & \\
\hline 1 & 3 & 0 & 108582 & 522 & 20323 & 309257 & 100729 & 538369 & 129 & 798460 & \\
\hline 2 & 5 & 0 & 133976 & 940 & 19645 & 299793 & 98516 & 550991 & 457 & 253333 & \\
\hline 4 & 2 & 0 & 125979 & 724 & 20263 & 308401 & 100517 & 554436 & 159 & 751538 & \\
\hline 5 & 2 & 6450 & 125979 & 1084 & 20109 & 306200 & 99944 & 557598 & 234 & 522386 & \\
\hline 1 & 4 & 0 & 144776 & 696 & 20148 & 306836 & 100173 & 571237 & 214 & 636557 & \\
\hline 2 & 6 & 0 & 160772 & 1128 & 19356 & 295758 & 97575 & 572332 & 597 & 229715 & \\
\hline 2 & 7 & 0 & 187567 & 1316 & 19117 & 292419 & 96793 & 594579 & 713 & 223637 & \\
\hline 1 & 5 & 0 & 180970 & 870 & 19971 & 304374 & 99606 & 604051 & 300 & 563630 & \\
\hline 4 & 3 & 0 & 188968 & 1086 & 19989 & 304590 & 99632 & 612092 & 291 & 607281 & \\
\hline 5 & 3 & 9675 & 188968 & 1626 & 19736 & 300952 & 98673 & 616377 & 416 & 435391 & \\
\hline 2 & 8 & 0 & 214362 & 1504 & 18961 & 290230 & 96279 & 618327 & 789 & 232250 & \\
\hline
\end{tabular}


Table 3 Cost and health outcome according to type and duration of school closure when $\boldsymbol{R}_{\boldsymbol{0}}=1.5$ (Continued)

\begin{tabular}{|c|c|c|c|c|c|c|c|c|c|c|}
\hline 1 & 6 & 0 & 217164 & 1044 & 19812 & 302170 & 99095 & 637197 & 377 & 536585 \\
\hline 2 & 9 & 0 & 241157 & 1692 & 18858 & 288799 & 95942 & 643065 & 838 & 248040 \\
\hline 4 & 4 & 0 & 251957 & 1448 & 19608 & 299290 & 98394 & 667801 & 476 & 489135 \\
\hline 2 & 10 & 0 & 267953 & 1880 & 18803 & 288023 & 95759 & 668657 & 865 & 269909 \\
\hline 1 & 7 & 0 & 253358 & 1218 & 19703 & 300654 & 98742 & 671239 & 429 & 549816 \\
\hline 5 & 4 & 12900 & 251957 & 2168 & 19239 & 293960 & 96967 & 672854 & 658 & 361133 \\
\hline 1 & 8 & 0 & 289552 & 1392 & 19639 & 299767 & 98536 & 706101 & 460 & 588611 \\
\hline 4 & 5 & 0 & 314946 & 1810 & 19151 & 292916 & 96892 & 722096 & 697 & 411700 \\
\hline 5 & 5 & 16125 & 314946 & 2710 & 18630 & 285363 & 94847 & 727200 & 955 & 305707 \\
\hline 1 & 9 & 0 & 325746 & 1566 & 19605 & 299302 & 98427 & 741514 & 477 & 642905 \\
\hline 4 & 6 & 0 & 377936 & 2172 & 18702 & 286631 & 95396 & 776493 & 915 & 373065 \\
\hline 1 & 10 & 0 & 361940 & 1740 & 19585 & 299025 & 98363 & 777173 & 486 & 703475 \\
\hline 5 & 6 & 19350 & 377936 & 3252 & 18018 & 276690 & 92681 & 781422 & 1255 & 275997 \\
\hline 4 & 7 & 0 & 440925 & 2534 & 18330 & 281412 & 94143 & 832277 & 1096 & 362429 \\
\hline 5 & 7 & 22575 & 440925 & 3794 & 17426 & 268283 & 90555 & 835970 & 1544 & 259543 \\
\hline 4 & 8 & 0 & 503914 & 2896 & 18058 & 277580 & 93217 & 889873 & 1228 & 370185 \\
\hline 5 & 8 & 25800 & 503914 & 4336 & 16965 & 261700 & 88870 & 892913 & 1771 & 258490 \\
\hline 4 & 9 & 0 & 566903 & 3258 & 17885 & 275152 & 92627 & 949309 & 1312 & 391782 \\
\hline 5 & 9 & 29025 & 566903 & 4878 & 16627 & 256878 & 87624 & 952179 & 1937 & 266957 \\
\hline 4 & 10 & 0 & 629893 & 3620 & 17789 & 273802 & 92297 & 1010161 & 1359 & 423098 \\
\hline 5 & 10 & 32250 & 629893 & 5420 & 16386 & 253424 & 86726 & 1013259 & 2056 & 281259 \\
\hline
\end{tabular}


Table 4 Cost and health outcome according to type and duration of school closure when $\boldsymbol{R}_{0}=\mathbf{2 . 0}$

\begin{tabular}{|c|c|c|c|c|c|c|c|c|c|c|c|}
\hline $\begin{array}{l}\text { Target } \\
\text { school }\end{array}$ & $\begin{array}{c}\text { Duration } \\
\text { (weeks) }\end{array}$ & $\begin{array}{c}\text { Cost of } \\
\text { lost learning } \\
(\$ 1000)\end{array}$ & $\begin{array}{l}\text { Lost productivity } \\
\text { due to school } \\
\text { closure }(\$ 1000)\end{array}$ & $\begin{array}{l}\text { Energy } \\
\text { savings } \\
(\$ 1000)\end{array}$ & $\begin{array}{l}\text { Health } \\
\text { care costs } \\
(\$ 1000)\end{array}$ & $\begin{array}{l}\text { Lost productivity } \\
\text { due to fatal } \\
\text { cases }(\$ 1000)\end{array}$ & $\begin{array}{l}\text { Lost productivity } \\
\text { due to sickness } \\
(\$ 1000)\end{array}$ & $\begin{array}{l}\text { Total cost } \\
(\$ 1000)\end{array}$ & $\begin{array}{c}\text { QALY gains } \\
\text { (compared to } \\
\text { no intervention) }\end{array}$ & $\begin{array}{l}\text { Cost per QALY } \\
\text { (compared to } \\
\text { no intervention) }\end{array}$ & ICER \\
\hline 0 & 0 & 0 & 0 & 0 & 28890 & 428137 & 138654 & 595682 & & & \\
\hline 3 & 4 & 12900 & 0 & 720 & 28215 & 419135 & 136843 & 596374 & 321 & 2155 & \\
\hline 3 & 5 & 16125 & 0 & 900 & 28049 & 416920 & 136411 & 596604 & 400 & 2306 & 2921 \\
\hline 3 & 1 & 3225 & 0 & 180 & 28846 & 427542 & 138529 & 597961 & 21 & 106854 & \\
\hline 3 & 3 & 9675 & 0 & 540 & 28491 & 422813 & 137570 & 598009 & 190 & 12224 & Dominated \\
\hline 3 & 6 & 19350 & 0 & 1080 & 27985 & 416062 & 136245 & 598562 & 431 & 6686 & 64224 \\
\hline 3 & 2 & 6450 & 0 & 360 & 28732 & 426018 & 138216 & 599056 & 76 & 44470 & Dominated \\
\hline 3 & 7 & 22575 & 0 & 1260 & 27964 & 415780 & 136190 & 601248 & 441 & 12628 & 267404 \\
\hline 3 & 8 & 25800 & 0 & 1440 & 27957 & 415695 & 136173 & 604186 & 444 & 19161 & 975711 \\
\hline 3 & 9 & 29025 & 0 & 1620 & 27955 & 415672 & 136169 & 607201 & 445 & 25907 & 3654485 \\
\hline 3 & 10 & 32250 & 0 & 1800 & 27955 & 415664 & 136167 & 610236 & 445 & 32714 & 11358909 \\
\hline 2 & 1 & 0 & 26795 & 188 & 28844 & 427532 & 138545 & 621528 & 22 & 1179444 & \\
\hline 1 & 1 & 0 & 36194 & 174 & 28853 & 427657 & 138575 & 631105 & 17 & 2029542 & \\
\hline 2 & 2 & 0 & 53591 & 376 & 28735 & 426112 & 138297 & 646358 & 73 & 691761 & \\
\hline 4 & 1 & 0 & 62989 & 362 & 28810 & 427096 & 138472 & 657005 & 38 & 1622566 & \\
\hline 5 & 1 & 3225 & 62989 & 542 & 28769 & 426546 & 138354 & 659342 & 58 & 1107041 & \\
\hline 1 & 2 & 0 & 72388 & 348 & 28752 & 426362 & 138363 & 665517 & 65 & 1082646 & \\
\hline 2 & 3 & 0 & 80386 & 564 & 28481 & 422818 & 137732 & 668853 & 192 & 380871 & \\
\hline 2 & 4 & 0 & 107181 & 752 & 28108 & 417981 & 136924 & 689442 & 366 & 256079 & \\
\hline 1 & 3 & 0 & 108582 & 522 & 28535 & 423576 & 137909 & 698080 & 166 & 618250 & \\
\hline 2 & 5 & 0 & 133976 & 940 & 27795 & 413930 & 136260 & 711021 & 512 & 225466 & \\
\hline 4 & 2 & 0 & 125979 & 724 & 28618 & 424608 & 138047 & 716527 & 128 & 944416 & \\
\hline 5 & 2 & 6450 & 125979 & 1084 & 28494 & 422945 & 137687 & 720470 & 187 & 665879 & \\
\hline 1 & 4 & 0 & 144776 & 696 & 28275 & 420231 & 137363 & 729949 & 287 & 467968 & \\
\hline 2 & 6 & 0 & 160772 & 1128 & 27636 & 411869 & 135925 & 735074 & 585 & 238117 & \\
\hline 2 & 7 & 0 & 187567 & 1316 & 27576 & 411079 & 135797 & 760703 & 614 & 268896 & \\
\hline 1 & 5 & 0 & 180970 & 870 & 28108 & 418079 & 137011 & 763298 & 365 & 459401 & \\
\hline 4 & 3 & 0 & 188968 & 1086 & 28179 & 418930 & 137085 & 772075 & 333 & 529302 & \\
\hline 5 & 3 & 9675 & 188968 & 1626 & 27906 & 415233 & 136270 & 776425 & 465 & 388791 & \\
\hline 2 & 8 & 0 & 214362 & 1504 & 27557 & 410834 & 135758 & 787007 & 622 & 307365 & \\
\hline
\end{tabular}


Table 4 Cost and health outcome according to type and duration of school closure when $\boldsymbol{R}_{\boldsymbol{0}}=\mathbf{2 . 0}$ (Continued)

\begin{tabular}{|c|c|c|c|c|c|c|c|c|c|c|}
\hline 1 & 6 & 0 & 217164 & 1044 & 28044 & 417253 & 136876 & 798292 & 395 & 513250 \\
\hline 2 & 9 & 0 & 241157 & 1692 & 27551 & 410765 & 135746 & 813528 & 625 & 348587 \\
\hline 4 & 4 & 0 & 251957 & 1448 & 27555 & 410851 & 135722 & 824637 & 624 & 366634 \\
\hline 5 & 4 & 12900 & 251957 & 2168 & 27050 & 403997 & 134214 & 827950 & 868 & 267629 \\
\hline 1 & 7 & 0 & 253358 & 1218 & 28022 & 416976 & 136830 & 833968 & 405 & 588668 \\
\hline 2 & 10 & 0 & 267953 & 1880 & 27550 & 410744 & 135743 & 840109 & 626 & 390639 \\
\hline 1 & 8 & 0 & 289552 & 1392 & 28017 & 416902 & 136818 & 869897 & 407 & 672986 \\
\hline 4 & 5 & 0 & 314946 & 1810 & 27034 & 404084 & 134582 & 878837 & 868 & 326324 \\
\hline 5 & 5 & 16125 & 314946 & 2710 & 26272 & 393758 & 132340 & 880731 & 1234 & 230988 \\
\hline 1 & 9 & 0 & 325746 & 1566 & 28015 & 416881 & 136815 & 905892 & 408 & 759953 \\
\hline 4 & 6 & 0 & 377936 & 2172 & 26753 & 400417 & 133965 & 936898 & 999 & 341470 \\
\hline 5 & 6 & 19350 & 377936 & 3252 & 25798 & 387502 & 131192 & 938526 & 1457 & 235261 \\
\hline 1 & 10 & 0 & 361940 & 1740 & 28015 & 416876 & 136814 & 941904 & 408 & 847747 \\
\hline 4 & 7 & 0 & 440925 & 2534 & 26645 & 399011 & 133728 & 997774 & 1050 & 383078 \\
\hline 5 & 7 & 22575 & 440925 & 3794 & 25597 & 384843 & 130703 & 1000849 & 1552 & 261045 \\
\hline 4 & 8 & 0 & 503914 & 2896 & 26611 & 398573 & 133654 & 1059855 & 1065 & 435700 \\
\hline 5 & 8 & 25800 & 503914 & 4336 & 25521 & 383838 & 130518 & 1065255 & 1588 & 295719 \\
\hline 4 & 9 & 0 & 566903 & 3258 & 26600 & 398435 & 133631 & 1122311 & 1070 & 492048 \\
\hline 5 & 9 & 29025 & 566903 & 4878 & 25494 & 383489 & 130454 & 1130488 & 1600 & 334181 \\
\hline 4 & 10 & 0 & 629893 & 3620 & 26597 & 398391 & 133623 & 1184883 & 1072 & 549693 \\
\hline 5 & 10 & 32250 & 629893 & 5420 & 25486 & 383386 & 130435 & 1196030 & 1604 & 374276 \\
\hline
\end{tabular}


Table 5 Cost and health outcome according to type and duration of school closure when $\boldsymbol{R}_{0}=\mathbf{2 . 5}$

\begin{tabular}{|c|c|c|c|c|c|c|c|c|c|c|c|}
\hline $\begin{array}{l}\text { Target } \\
\text { school }\end{array}$ & $\begin{array}{c}\text { Duration } \\
\text { (weeks) }\end{array}$ & $\begin{array}{l}\text { Cost of lost } \\
\text { learning } \\
(\$ 1000)\end{array}$ & $\begin{array}{l}\text { Lost productivity } \\
\text { due to school } \\
\text { closure }(\$ 1000)\end{array}$ & $\begin{array}{l}\text { Energy } \\
\text { savings } \\
(\$ 1000)\end{array}$ & $\begin{array}{l}\text { Health } \\
\text { care costs } \\
(\$ 1000)\end{array}$ & $\begin{array}{l}\text { Lost productivity } \\
\text { due to fatal } \\
\text { cases }(\$ 1000)\end{array}$ & $\begin{array}{l}\text { Lost productivity } \\
\text { due to sickness } \\
(\$ 1000)\end{array}$ & $\begin{array}{l}\text { Total cost } \\
(\$ 1000)\end{array}$ & $\begin{array}{c}\text { QALY gains } \\
\text { (compared to } \\
\text { no intervention) }\end{array}$ & $\begin{array}{l}\text { Cost per QALY } \\
\text { (compared to } \\
\text { no intervention) }\end{array}$ & ICER \\
\hline 0 & 0 & 0 & 0 & 0 & 32961 & 479607 & 155079 & 667646 & & & \\
\hline 3 & 1 & 3225 & 0 & 180 & 32928 & 479185 & 155005 & 670162 & 16 & 160991 & \\
\hline 3 & 3 & 9675 & 0 & 540 & 32544 & 474295 & 154205 & 670179 & 195 & 12994 & \\
\hline 3 & 4 & 12900 & 0 & 720 & 32367 & 472045 & 153864 & 670456 & 277 & 10150 & 3380 \\
\hline 3 & 2 & 6450 & 0 & 360 & 32801 & 477565 & 154728 & 671184 & 75 & 47003 & Dominated \\
\hline 3 & 5 & 16125 & 0 & 900 & 32318 & 471424 & 153771 & 672739 & 299 & 17011 & 101226 \\
\hline 3 & 6 & 19350 & 0 & 1080 & 32308 & 471296 & 153752 & 675626 & 304 & 26248 & 620315 \\
\hline 3 & 7 & 22575 & 0 & 1260 & 32306 & 471271 & 153749 & 678641 & 305 & 36059 & 3386921 \\
\hline 3 & 8 & 25800 & 0 & 1440 & 32306 & 471267 & 153748 & 681681 & 305 & 46005 & 20007697 \\
\hline 3 & 9 & 29025 & 0 & 1620 & 32306 & 471266 & 153748 & 684725 & 305 & 55979 & 126703892 \\
\hline 3 & 10 & 32250 & 0 & 1800 & 32306 & 471266 & 153748 & 687770 & 305 & 65955 & 289245859 \\
\hline 2 & 1 & 0 & 26795 & 188 & 32929 & 479210 & 155022 & 693768 & 15 & 1764356 & \\
\hline 1 & 1 & 0 & 36194 & 174 & 32929 & 479216 & 155031 & 703195 & 15 & 2442399 & \\
\hline 2 & 2 & 0 & 53591 & 376 & 32811 & 477750 & 154823 & 718598 & 69 & 738185 & \\
\hline 4 & 1 & 0 & 62989 & 362 & 32899 & 478844 & 154977 & 729347 & 28 & 2168767 & \\
\hline 5 & 1 & 3225 & 62989 & 542 & 32871 & 478484 & 154908 & 731936 & 42 & 1538432 & \\
\hline 1 & 2 & 0 & 72388 & 348 & 32797 & 477600 & 154839 & 737276 & 75 & 934187 & \\
\hline 2 & 3 & 0 & 80386 & 564 & 32504 & 473932 & 154337 & 740595 & 210 & 348001 & \\
\hline 2 & 4 & 0 & 107181 & 752 & 32174 & 469835 & 153856 & 762295 & 359 & 263354 & \\
\hline 1 & 3 & 0 & 108582 & 522 & 32532 & 474332 & 154456 & 769379 & 196 & 520297 & \\
\hline 2 & 5 & 0 & 133976 & 940 & 32013 & 467836 & 153631 & 786516 & 432 & 275032 & \\
\hline 4 & 2 & 0 & 125979 & 724 & 32671 & 476022 & 154614 & 788561 & 133 & 907803 & \\
\hline 5 & 2 & 6450 & 125979 & 1084 & 32558 & 474572 & 154337 & 792811 & 187 & 670647 & \\
\hline 1 & 4 & 0 & 144776 & 696 & 32315 & 471663 & 154148 & 802206 & 294 & 457624 & \\
\hline 2 & 6 & 0 & 160772 & 1128 & 31970 & 467302 & 153571 & 812487 & 452 & 320722 & \\
\hline 1 & 5 & 0 & 180970 & 870 & 32242 & 470771 & 154046 & 837160 & 327 & 518523 & \\
\hline 2 & 7 & 0 & 187567 & 1316 & 31962 & 467200 & 153560 & 838973 & 455 & 376283 & \\
\hline 4 & 3 & 0 & 188968 & 1086 & 32117 & 469165 & 153760 & 842924 & 386 & 453852 & \\
\hline 5 & 3 & 9675 & 188968 & 1626 & 31806 & 465143 & 153021 & 846987 & 533 & 336228 & \\
\hline 2 & 8 & 0 & 214362 & 1504 & 31960 & 467181 & 153558 & 865557 & 456 & 434015 & \\
\hline
\end{tabular}


Table 5 Cost and health outcome according to type and duration of school closure when $\boldsymbol{R}_{\boldsymbol{0}}=\mathbf{2 . 5}$ (Continued)

\begin{tabular}{|c|c|c|c|c|c|c|c|c|c|c|}
\hline 1 & 6 & 0 & 217164 & 1044 & 32226 & 470573 & 154023 & 872943 & 334 & 614247 \\
\hline 2 & 9 & 0 & 241157 & 1692 & 31960 & 467177 & 153557 & 892159 & 456 & 492180 \\
\hline 4 & 4 & 0 & 251957 & 1448 & 31531 & 461895 & 152891 & 896827 & 653 & 351186 \\
\hline 5 & 4 & 12900 & 251957 & 2168 & 30971 & 454663 & 151625 & 899947 & 916 & 253572 \\
\hline 1 & 7 & 0 & 253358 & 1218 & 32224 & 470539 & 154019 & 908922 & 335 & 719170 \\
\hline 2 & 10 & 0 & 267953 & 1880 & 31960 & 467176 & 153557 & 918766 & 456 & 550486 \\
\hline 1 & 8 & 0 & 289552 & 1392 & 32223 & 470532 & 154019 & 944934 & 336 & 825928 \\
\hline 4 & 5 & 0 & 314946 & 1810 & 31242 & 458297 & 152470 & 955145 & 784 & 366760 \\
\hline 5 & 5 & 16125 & 314946 & 2710 & 30530 & 449119 & 150906 & 958916 & 1118 & 260600 \\
\hline 1 & 9 & 0 & 325746 & 1566 & 32223 & 470531 & 154019 & 980953 & 336 & 933116 \\
\hline 4 & 6 & 0 & 377936 & 2172 & 31161 & 457290 & 152353 & 1016567 & 821 & 425217 \\
\hline 1 & 10 & 0 & 361940 & 1740 & 32223 & 470531 & 154019 & 1016972 & 336 & 1040374 \\
\hline 5 & 6 & 19350 & 377936 & 3252 & 30395 & 447425 & 150689 & 1022542 & 1179 & 300960 \\
\hline 4 & 7 & 0 & 440925 & 2534 & 31145 & 457092 & 152330 & 1078958 & 828 & 496882 \\
\hline 5 & 7 & 22575 & 440925 & 3794 & 30360 & 446990 & 150633 & 1087690 & 1195 & 351506 \\
\hline 4 & 8 & 0 & 503914 & 2896 & 31142 & 457055 & 152326 & 1141540 & 829 & 571548 \\
\hline 5 & 8 & 25800 & 503914 & 4336 & 30354 & 446910 & 150623 & 1153266 & 1198 & 405402 \\
\hline 4 & 9 & 0 & 566903 & 3258 & 31142 & 457047 & 152325 & 1204158 & 829 & 646844 \\
\hline 5 & 9 & 29025 & 566903 & 4878 & 30353 & 446893 & 150621 & 1218917 & 1199 & 459966 \\
\hline 4 & 10 & 0 & 629893 & 3620 & 31141 & 457045 & 152324 & 1266783 & 829 & 722298 \\
\hline 5 & 10 & 32250 & 629893 & 5420 & 30352 & 446889 & 150620 & 1284584 & 1199 & 514689 \\
\hline
\end{tabular}


comparison, our selected strategies involved much shorter closure durations of 4-8 weeks. One reason for this large discrepancy could be that they used early triggers. In addition, their model has a very long serial interval of 9 days, whereas our model has a serial interval of approximately 4 days due to the infectious profile, which we believe is more in agreement with data [38].

The present work highlights the potential importance of school closure among students who do not need parental care. The benefit of school closure interventions targeting this group appears to have escaped notice in the literature. Our results suggest that closing secondary school alone can decrease the peak prevalence of symptomatic infection by $10-20 \%$ while incurring no loss of productivity for parents. Hence, school closure for children over 12 years could have important implications for the functioning of the healthcare system during the surge of a pandemic, when the capacity of health services may be pressured. We note that in Norway laptop computers are mandatory equipment in secondary schools and an organized computer network ("Fronter") for communication between students and teachers in primary and secondary schools is already in place. It would therefore be possible to plan for sustained teaching and learning during an extended school closure, making secondary school closure even more cost-effective. However, for the strategy to be effective, it is important that students actually follow the recommendations and isolate themselves. This may be difficult to achieve for extended periods of time.

The health-economic evaluation in this study was based on estimates of age-specific health-outcome from previous pandemics [26]. If we scale up the results in the baseline scenarios for $R_{O}=1.5-2.5$ pandemics to the national level (Oslo comprises approximately 12\% of Norwegian population), our results correspond to 16 000-26 000 hospitalizations and 4 900-8 200 deaths in Norway with an attack rate ranging from $37-58 \%$. In comparison, the yearly influenza epidemics (attack rate of $5-10 \%)$ results in approximately 2700 cases of hospitalizations [34] and approximately 1000 deaths [39]. Adjusting for the difference in attack rates, this indicates that our results are in reasonable agreement with findings from the seasonal epidemics; however, the numbers are difficult to compare because the seasonal epidemics primarily affect the elderly population.

Our study has several limitations. Firstly, the agespecific contact rate data were adopted from a Dutch study, as no Norwegian data on social mixing is currently available. The contact pattern in Norway may differ, in particular due to the high attendance rates in kindergarten and high employment rate of women. Secondly, the effect of school closure on the contact pattern in the population is not well documented in the literature and is uncertain. However, our choices were guided by observation from weekends and holidays and previous school closures in Oslo due to strikes, etc. Thirdly, the cost of lost learning is uncertain. We used tuition fees as a proxy for the value of learning, but private schools are primarily used by people with higher incomes and the tuition fee may therefore overstate the value of lost learning. Fourthly, productivity losses may be overestimated because some parents who are away from work may be absent anyway because they have influenza themselves. Fifthly, energy savings in schools during school closure may be partly off-set by higher energy use in homes. However, energy in Norway is cheap and only small proportions of households have day-time energy saving systems according to the governmental energy saving organization. Lastly, we have considered school closure as a single strategy. Combining school closure with other interventions such as use of antiviral medications or other social distancing measures might change the conclusions about optimal duration of school closure, and the target group.

\section{Conclusions}

School closure has moderate impact on influenza disease and may incur substantial economic costs in terms of lost productivity from care-taking parents absent from work. Closing secondary schools, assuming children above 12 years would not need parental care, is a costeffective strategy from a societal perspective. With the current willingness to pay in Norway, closing kindergartens and primary schools is not a cost-effective policy to mitigate an influenza pandemic, unless the case fatality rates are high. Reliable information on influenza mortality is therefore of primary importance to inform decision-making on school closure. Finally, we note that the perspective of the policy maker is crucial for optimal design of school closure. If the policy maker disregards productivity losses, the optimal strategy is to close as many school as possible for as long time as possible.

\section{Additional file}

Additional file 1: Online_additional_materials.doc, 1233K.

\section{Competing interests}

The authors declare that they have no competing interest.

\section{Authors' contributions}

$Y X$ originated the idea and drafted the paper. $Y X$ and BFB constructed the mathematical model while YX and ISK conducted the health economic evaluation. BFB and ISK reviewed and revised the manuscript. All authors read and approved the final manuscript.

\section{Acknowledgements}

We are grateful to Kirsten E. Dybendal at Statistics Norway for providing detailed data on population statistics and to Gianpaolo Scalia Tomba at the Department of Mathematics, University of Rome for suggestions in the 
disease modelling. Arna Desser at Department of Health Management and Health Economics, University of Oslo, has provided valuable suggestions on heath economics and helped to improve the language.

\section{Funding source}

Yiting Xue was supported by the Norwegian Research Council through project number 177401/N50 and Birgitte Freiesleben de Blasio was supported by the Norwegian Research Council through project number 166056/N50.

\section{Author details}

'Department of Biostatistics, Institute of Basic Medical Sciences, University of Oslo, Oslo, Norway. ${ }^{2}$ Department of Infectious Disease Epidemiology, Division of Infectious Disease Control, Norwegian Institute of Public Health, Oslo, Norway. ${ }^{3}$ Department of Health Management and Health Economics, Institute of Health and Society, University of Oslo, Oslo, Norway.

Received: 22 June 2012 Accepted: 16 October 2012

Published: 9 November 2012

\section{References}

1. Cox NJ, Fukuda K: Influenza. Infect Dis Clin North Am 1998, 12:27-38

2. Yang $Y$, Sugimoto JD, Halloran ME, Basta NE, Chao DL, Matrajt L, et al: The transmissibility and control of pandemic influenza $A(\mathrm{H} 1 \mathrm{~N} 1)$ virus. Science 2009, 326:729-733.

3. Cauchemez S, Ferguson NM, Wachtel C, Tegnell A, Saour G, Duncan B, et al: Closure of schools during an influenza pandemic. Lancet Infect Dis 2009, 9:473-481

4. Hatchett RJ, Mecher CE, Lipsitch M: Public health interventions and epidemic intensity during the 1918 influenza pandemic. Proc Natl Acad Sci U S A 2007, 104:7582-7587.

5. Markel H, Lipman HB, Navarro JA, Sloan A, Michalsen JR, Stern AM, et al: Nonpharmaceutical interventions implemented by US cities during the 1918-1919 influenza pandemic. JAMA 2007 298:644-654.

6. Hens N, Ayele GM, Goeyvaerts N, Aerts M, Mossong J, Edmunds JW, et al: Estimating the impact of school closure on social mixing behaviour and the transmission of close contact infections in eight European countries. BMC Infect Dis 2009, 9:187.

7. Cowling BJ, Lau EH, Lam CL, Cheng CK, Kovar J, Chan KH, et al: Effects of school closures, 2008 winter influenza season, Hong Kong. Emerg Infect Dis 2008, 14:1660-1662.

8. Glass K, Barnes B: How much would closing schools reduce transmission during an influenza pandemic? Epidemiology 2007, 18:623-628.

9. Lee BY, Brown ST, Cooley P, Potter MA, Wheaton WD, Voorhees RE, et al: Simulating School Closure Strategies to Mitigate an Influenza Epidemic. J Public Health Manag Pract 2010, 16(3):252-61.

10. Glass RJ, Glass LM, Beyeler WE, Min HJ: Targeted social distancing design for pandemic influenza. Emerg Infect Dis 2006, 12:1671-1681.

11. Halder N, Kelso JK, Milne GJ: Analysis of the effectiveness of interventions used during the 2009 A/H1N1 influenza pandemic. BMC Publ Health 2010, 10:168.

12. Halder N, Kelso JK, Milne GJ: Developing guidelines for school closure interventions to be used during a future influenza pandemic. BMC Infect Dis 2010, 10:221.

13. Sadique MZ, Adams EJ, Edmunds WJ: Estimating the costs of school closure for mitigating an influenza pandemic. BMC Publ Health 2008 8:135.

14. Lempel H, Epstein JM, Hammond RA: Economic cost and health care workforce effects of school closures in the U.S, RRN1051. PLOS Curr Influenza 2009, doi:10.1371/currents.RRN1051.

15. House T, Baguelin M, Van Hoek AJ, White PJ, Sadique Z, Eames K, et al: Modelling the impact of local reactive school closures on critical care provision during an influenza pandemic. Proc Biol Sci 2011, 278:2753-2760.

16. Halder N, Kelso JK, Milne GJ: Cost-effective strategies for mitigating a future influenza pandemic with H1N1 2009 characteristics. PLOS One 2011, 6:e22087.

17. Brown ST, Tai JH, Bailey RR, Cooley PC, Wheaton WD, Potter MA, et al: Would school closure for the $2009 \mathrm{H} 1 \mathrm{~N} 1$ influenza epidemic have been worth the cost? A computational simulation of Pennsylvania. BMC Publ Health 2011, 11:353.

18. Perlroth DJ, Glass RJ, Davey VJ, Cannon D, Garber AM, Owens DK: Health Outcomes and Costs of Community Mitigation Strategies for an Influenza Pandemic in the United States. Clin Infect Dis 2010, 50:165-174.

19. Sander B, Nizam A, Garrison LP, Postma MJ, Halloran ME, Longini IM: Economic evaluation of influenza pandemic mitigation strategies in the US using a stochastic microsimulation influenza model. Value Health 2007, 10:A19.

20. Araz OM, Damien P, Paltiel DA, Burke S, Geijn BV, Galvani A, et al: Simulating school closure policies for cost effective pandemic decision making. BMC Publ Health 2012, 12:449.

21. Statistics Norway; http://www.ssb.no/. 16-12-2010

22. Keeling MJ, Rohani P: Modeling Infectious Diseases in Humans and Animals. 2007.

23. Carrat F, Vergu E, Ferguson NM, Lemaitre M, Cauchemez S, Leach S, et al: Time lines of infection and disease in human influenza: a review of volunteer challenge studies. Am J Epidemiol 2008, 167:775-785.

24. Longini IM, Halloran ME, Nizam A, Yang Y: Containing pandemic influenza with antiviral agents. Am J Epidemiol 2004, 159:623-633.

25. Germann TC, Kadau K, Longini IM Jr, Macken CA: Mitigation strategies for pandemic influenza in the United States. Proc Natl Acad Sci U S A 2006, 103:5935-5940.

26. Fraser $C$, Riley $S$, Anderson RM, Ferguson NM: Factors that make an infectious disease outbreak controllable. Proc Natl Acad Sci U S A 2004, 101:6146-6151.

27. Fraser C, Donnelly CA, Cauchemez S, Hanage WP, Van Kerkhove MD, Hollingsworth TD, et al: Pandemic potential of a strain of influenza A (H1N1): early findings. Science 2009, 324:1557-1561.

28. Lau LL, Cowling BJ, Fang VJ, Chan KH, Lau EH, Lipsitch M, et al: Viral shedding and clinical illness in naturally acquired influenza virus infections. J Infect Dis 2010, 201:1509-1516.

29. Wallinga J, Teunis P, Kretzschmar M: Using data on social contacts to estimate age-specific transmission parameters for respiratory-spread infectious agents. Am J Epidemiol 2006, 164:936-944.

30. Gani R, Hughes H, Fleming D, Griffin T, Medlock J, Leach S: Potential impact of antiviral drug use during influenza pandemic. Emerg Infect Dis 2005 11:1355-1362

31. Comay Y, Melnik A, Pollatschek MA: The Option Value of Education and the Optimal Path for Investment in Human Capital. Int Econ Rev 1973, 14:421-435.

32. Maurin $E$, McNally S: Vive la revolution! Long-term educational returns of 1968 to the angry students. J Labor Econ 2008, 26:1-33.

33. Meltzer Ml, Cox NJ, Fukuda K: The economic impact of pandemic influenza in the United States: priorities for intervention. Emerg Infect Dis 1999, 5:659-671.

34. Xue Y, Kristiansen IS, de Blasio BF: Modeling the cost of influenza: the impact of missing costs of unreported complications and sick leave. BMC Publ Health 2010, 10:724

35. O'Brien BJ, Goeree R, Blackhouse G, Smieja M, Loeb M: Oseltamivi for treatment of influenza in healthy adults: pooled trial evidence and cost-effectiveness model for Canada. Value Health 2003, 6:116-125.

36. Cauchemez S, Valleron AJ, Boelle PY, Flahault A, Ferguson NM: Estimating the impact of school closure on influenza transmission from Sentinel data. Nature 2008, 452:750-754

37. The Norwegian Directorate of Health: Health effects in social-economics analysis (Helseeffekter i samfunnsøkonomiske analyser); 2007. http://www. helsedirektoratet.no/publikasjoner/helseeffekter-i-samfunnsokonomiskeanalyser-/Sider/default.aspx

38. Boelle PY, Ansart S, Cori A, Valleron AJ: Transmission parameters of the A/H1N1 (2009) influenza virus pandemic: a review. Influenza Other Respi Viruses 2011, 5:306-316

39. Gran JM, Iversen B, Hungnes O, Aalen OO: Estimating influenza-related excess mortality and reproduction numbers for seasonal influenza in Norway, 1975-2004. Epidemiol Infect 2010, 138:1559-1568.

doi:10.1186/1471-2458-12-962

Cite this article as: Xue et al:: Dynamic modelling of costs and health consequences of school closure during an influenza pandemic. BMC Public Health 2012 12:962. 